\title{
Inhibition of Ethanol Neurotoxicity by Treatment with Growth Factors and Estrogen
}

\author{
Jason A. Zell, M.S., Jeremy R. Montague, Ph.D., Tomas F. Lopez, B.S., and \\ Laura M. Mudd*, Ph.D.
}

\begin{abstract}
Ethanol ingestion by pregnant women is the primary cause of fetal alcohol syndrome, which is characterized by brain abnormalities and decreased mental capacity. In the present study, cultured neurons from embryonic rat cortices were used to study the effects of ethanol on cell survival and the potential for neuroprotection by certain growth factors and estrogen. Neurons were grown in the presence of a glial plane and in the absence of serum. Survival was assessed following chronic treatment with ethanol $(45 \mathrm{mM})$ in the presence and absence of either nerve growth factor (NGF, $100 \mathrm{ng} / \mathrm{ml}$ ), basic fibroblast growth factor (bFGF, $5 \mathrm{ng} / \mathrm{ml}$ ), insulin-like growth factor I or II (IGF-I, IGFII, both $10 \mathrm{ng} / \mathrm{ml}$ ), or estrogen (Es, 10nM) added on days one and four in vitro. On day in vitro 4 (DIV 4) ethanol effects on neuronal viability were significantly prevented by NGF, bFGF, IGF-I, and Es. DIV 6 survival of ethanol-treated neurons was increased significantly by treatment with NGF, bFGF, IGF-I, IGF-II, and Es. Nerve growth factor, bFGF, and IGF-I effects were shown to be dose-dependent. Administration of 1-100 ng/ml NGF, 0.05-5 ng/ml bFGF and 0.1-10ng/ml IGF-I led to statistically significant effects at 10,5, and $1 \mathrm{ng} / \mathrm{ml}$, respectively. Thus, ethanol's effect on neuronal survival may be inhibited by simultaneous treatment with physiological doses of these factors.
\end{abstract}

\section{INTRODUCTION}

Ethanol is a known teratogen in humans and its ingestion by pregnant women is the primary cause of fetal alcohol syndrome (FAS), as well as the milder manifestation known as fetal alcohol effect (1). The decreases in mental capacity and delayed maturation in humans following fetal alcohol exposure are associated with abnormalities in the number and structure of neurons throughout the cortex and other brain areas (2). In humans, ethanol has neuropathic effects primarily when administered after the first 20 weeks in utero (3). The major effects of ethanol are thought to be mediated by ethanol itself, since in animal models most of ethanol's primary metabolite, acetaldehyde, is

\footnotetext{
* To whom correspondence should be addressed: School of Natural and Health Sciences, Barry University,11300 N.E. 2nd Avenue, Miami Shores, Florida, USA 33161; 1mudd@ mail.barry.edu
}

metabolized by the placenta, whereas ethanol crosses the placenta (3). However, recent studies have shown that rat fetal brain tissue can itself form acetaldehyde from ethanol via catalase (4), suggesting that acetaldehyde may play a role in fetal brain response to ethanol.

Rats have been used extensively as a model for studying FAS and for understanding ethanol's effects on neuronal survival $(5,6)$. Prenatal ethanol exposure causes a significant decrease in birth weight, microencephaly, memory deficits, and learning and behavioral abnormalities in rat pups raised under an FAS model system, as well as altered neurotransmitter levels (5,7-10). Prenatal ethanol exposure also causes a decrease in the number of pyramidal neurons in the rat hippocampus (5). Prenatal exposure to ethanol induces loss of mass in the rat cerebral cortex due to decreased numbers of neurons and glia, and it also causes a decrease in neuronal migration (11). 
The effects of ethanol on the central nervous system (CNS) are dependent upon the stage of embryonic development in which exposure occurs. The first half of gestation (days 1-9) in the rat corresponds roughly to the first trimester in the human, with ethanol administration leading to gross abnormalities in the brain (2). The second half of gestation in rats (days 10-21) corresponds to the second trimester in the human; in this proliferative stage in which neuronal populations are being developed, ethanol reduces the number of neurons (2). The third trimester in the human is similar to the postnatal period from days 1 to 10 in the rat (2). Chronic ethanol treatment of pregnant rats between embryonic days 6-14 days can result in either anencephaly or hydrocephaly (12); chronic treatment given between embryonic days 15-21 leads to altered proliferation and differentiation of neurons (12). Microencephaly may be caused by ethanol exposure during any period although it is particularly severe when given to neonatal rats on postnatal days 4-10 in a period corresponding to the third trimester of human brain development (7). Furthermore, ethanol causes decreases in the survival of neurons of the rat CNS $(13,14)$, including cortical neurons (13). In one study, three-month-old rat pups that had been treated prenatally with ethanol exhibited a $33 \%$ smaller volume of cortical neurons in area 3 of the primary somatosensory cortex when compared to rats raised similarly but grown on a control (no ethanol) diet (13).

Neuroprotective growth factors and hormones have been shown to protect neurons from a diverse variety of insults both in vitro and in vivo, for example, serum deprivation, oxidative stress, $\beta$-amyloid peptide, excitotoxicity, ischemia, and axotomy (15-20). Mitogenic growth factors ameliorate responses to ethanol differentially within the CNS (21). Nerve growth factor (NGF) and basic fibroblast growth factor (bFGF) protect rat cerebellar granule cells challenged with ethanol, while insulin-like growth factor I (IGF-I) does not (22). Nerve growth factor and bFGF also protect septal and hippocampal neurons from ethanol (23-24). This is in spite of the fact that ethanol decreases the expression of the low affinity p75 NGF receptor, but not the expression of the high affinity TrkA NGF receptor in cultured cortical neurons (25). In addition, NGF protects cholinergic neurons from ethanol (26), and decreased ethanol susceptibility has been observed in IGF-I transgenic mice (27). Estradiol and ethanol interact differently in different parts of the brain (28), which may explain gender differences in ethanol effects.

In the present study, we examined the effects of IGFI and IGF-II at concentrations similar to those expressed in brain (29), NGF and bFGF at concentrations known to affect neuronal function (30-32), and estrogen (Es) at the concentration of receptor affinity in the brain (33), in an ethanol neurotoxicity system. In vitro primary culture was used for this research so that some of the complicating factors that occur in in vivo models (e.g,. placental effects, effects of the blood brain barrier) might be better controlled. Specifically, we used a bilaminar culture system (34-36) that maintained separation of glia from neurons, while still permitting their interaction. Also, all experiments were performed in the absence of serum, thus eliminating some of the confounding effects of serum (i.e., the presence of unknown quantities of growth factors). Another advantage of using this culture system was that ethanol and growth factors could be administered directly to the neurons, thus, the actual concentration of ethanol to which the neurons were exposed could be quantified.

The primary cultures used in our experiments were prepared from rat brains that were surgically removed from pregnant mothers at embryonic day 16 (E16), a point at which in vivo ethanol administration leads to neuronal abnormalities (12). Thus, the cortical neurons used in this study were at an appropriate stage for investigating effects due to ethanol (see above). Using a bilaminar glial-neuron culture system, we set out to determine if NGF, bFGF, IGF-I, IGF-II, or Es could significantly inhibit the detrimental effect of ethanol on survival of cortical neurons cultured from the embryonic rat. Additionally, we tested the relationship between the concentration of neuroprotective agent administered and the percent cell survival.

\section{METHODS}

\section{Dissection and Cell Culture \\ Glial plane}

Glial cultures were prepared from E16 SpragueDawley rat (Charles River, Raleigh, NC) cortices 14 days prior to the neuronal dissection. Cortices were dissected and minced in a sterile environment in calcium and magnesium-free Hank's balanced salt solution (HBSS) at $20^{\circ} \mathrm{C}$ as described previously (30). Cortical tissue was digested with trypsin (Sigma, St. Louis, MO; 20 minutes at $37^{\circ} \mathrm{C}, 0.1 \%$ ), subjected to treatment with DNAse (Sigma, 5 minutes at $37^{\circ} \mathrm{C}$, $0.3 \mathrm{mg} / \mathrm{ml}$ with $0.5 \mathrm{mg} / \mathrm{ml} \mathrm{MgSO}_{4}$ ), and centrifuged at $1000 \mathrm{x} g$ for 5 minutes. Cells were mechanically separated by being drawn up five times in a micropipette, resuspended in $10 \%$ horse serum (Hyclone; Logan, UT) in Dulbecco's modified Eagle Medium (DMEM, Hyclone). Cells were then plated onto uncoated $100 \mathrm{~mm}$ diameter tissue culture dishes (Corning; Corning, NY) and transferred to $60 \mathrm{~mm}$ tissue culture dishes 6 - 8 days prior to neuronal dissection. 
Table 1. Ethanol evaporation rate. Ethanol concentrations from media samples with ethanol only treatment are reported in $\mathrm{mM}$ at time of initial ethanol administration and at 2, 4, and 6 hours post-ethanol administration, as determined by UV spectrophotometry.

\begin{tabular}{ccc}
\hline \hline Time (hour) & \multicolumn{2}{c}{ Ethanol (mM) } \\
& Mean & \\
\hline & & \\
0 & 45.0 & 2.3 \\
2 & 42.0 & 0.8 \\
4 & 37.4 & 1.4 \\
6 & 29.6 & 0.8 \\
\hline \hline
\end{tabular}

SEM: standard error of the mean

One day prior to the neuronal dissection the media in the plates containing the glial cells was replaced with $4 \mathrm{ml} \mathrm{N2.1} \mathrm{medium} \mathrm{(DMEM} \mathrm{supplemented} \mathrm{with} \mathrm{20nM}$ progesterone (Sigma)), 100mM putrescine (Sigma), $30 \mathrm{nM}$ selenium dioxide (Sigma), $5 \mathrm{mg} / \mathrm{ml}$ insulin (GIBCO; Grand Island, NY), $100 \mathrm{mg} / \mathrm{ml}$ transferrin (Sigma), 55mg/ml pyruvate (Sigma), $500 \mathrm{mg} / \mathrm{ml}$ bovine serum albumin (Sigma), and $2 \mathrm{mM}$ L-glutamine (GIBCO).

\section{Neuronal plane}

The cortical neurons were dissected from E16 Sprague-Dawley rat brains in HBSS and incubated with trypsin $\left(20\right.$ minutes at $\left.37^{\circ} \mathrm{C}, 0.1 \%\right)$, followed by addition of DNAse $\left(5\right.$ minutes at $37^{\circ} \mathrm{C}, 0.3 \mathrm{mg} / \mathrm{ml}$ with $\left.0.5 \mathrm{mg} / \mathrm{ml} \mathrm{MgSO}_{4}\right)$. Cells were centrifuged at $1000 \mathrm{x}$ $\mathrm{g}$, resuspended to a final concentration of $1 \times 10^{5}$ cells/ml in DMEM containing $10 \%$ horse serum and 2mM L-glutamine (Hyclone). These cells were plated onto silane-coated glass coverslips (Fisher; Fair Lawn, NJ) (37) with paraplast feet, $3 \times 10^{4}$ cells/coverslip. Cells were allowed to adhere to the coverslips for 2 hours, after which they were inverted over the 40-60\% confluent glial planes in a variation (30) of a previously published method (34-36). Glial and neuronal planes were maintained at a distance of about $1 \mathrm{~mm}$ from each other for the duration of the experiment. After one day in vitro, $1 \times 10^{-5} \mathrm{M}$ cytosine arabinofuranoside (GIBCO) was added to prevent glial proliferation. All cells were maintained in a humidified $37^{\circ} \mathrm{C}, \quad 95 \%$ air $/ 5 \% \quad \mathrm{CO}_{2}$ incubator (NUAIRE) until use. One fourth of the N2.1 media was replaced every four days.

\section{Ethanol Evaporation Experiment}

Triplicate samples of $100 \mathrm{ml}$ were taken from each of three separate culture dishes immediately after ethanol addition to the media on DIV 4 . Cells were then placed in a $37^{\circ} \mathrm{C}$ incubator and subsequent $100 \mathrm{ml}$ samples were taken at 2 hours, 4 hours, and 6 hours. All samples were analyzed by UV spectrophotometry for absorbance data. Absorbance data was compared to that of an ethanol standard via use of an alcohol diagnostic kit (Sigma Diagnostic ethanol kit \#5133) and values were converted into the amount of ethanol per volume media (represented in mM concentrations).

The rate of ethanol evaporation from the media was determined on DIV 4 over a period of 6 hours by UV spectrophotometry (Table 1). The initial concentration of ethanol in the media samples was $45.0 \pm 2.3 \mathrm{mM}$ (mean $\pm(\mathrm{SEM}))$. This concentration progressively declined over the experimental time period, and after six hours the concentration of ethanol remaining in the media was $29.6 \pm 0.8 \mathrm{~mm}$ (mean $\pm \mathrm{SEM}$ ). Thus a $34.3 \%$ decrease in the concentration of ethanol in the media was observed after six hours at $37^{\circ} \mathrm{C}$.

\section{Treatment of Experimental Groups}

\section{Survival experiment}

Cells were treated on DIV 1 and again on DIV 4 with either $45 \mathrm{mM}$ ethanol (Florida Distillery, Lake Alfred, FL), or $45 \mathrm{mM}$ ethanol plus one of the following: 10nM Es (Sigma), 100ng/ml NGF (UBI, Lake Placid, NY), 5ng/ml bFGF (UBI), 10ng/ml IGFI (UBI), or 10ng/ml IGF-II (UBI). Control dishes were treated with DMEM only, and isovolumetric quantity of fluid per dish was achieved by adding DMEM to each of the experimental treatment dishes. Cell viability was determined on DIV 1, and subsequently on DIV 4 and DIV 6 for all treatments.

\section{Dose-dependence experiment}

Cells were treated on DIV 1 and again on DIV 4, and five classes of treatments were set up: NGF, bFGF, IGFI, IGF-II, and Es. All treatments were performed in triplicate with separate control and ethanol treatments. For each class of treatments, the original concentration (i.e., the concentration used for the survival experiments) of growth factor/estrogen, along with a 10 and 100 fold dilution, were tested. The NGF class of treatments then consisted of $45 \mathrm{mM}$ ethanol plus $100 \mathrm{ng} / \mathrm{ml}, 10 \mathrm{ng} / \mathrm{ml}$ $\mathrm{NGF}$, and 1ng/ml NGF, as well as control and ethanol $(45 \mathrm{mM})$ treatments. The bFGF treatment class contained $45 \mathrm{mM}$ ethanol plus $5 \mathrm{ng} / \mathrm{ml} \mathrm{bFGF}, 0.5 \mathrm{ng} / \mathrm{ml} \mathrm{bFGF}$, and $0.05 \mathrm{ng} / \mathrm{ml} \mathrm{bFGF}$, as well as control and $45 \mathrm{mM}$ ethanol treatments. The IGF-I and IGF-II classes contained $45 \mathrm{mM}$ ethanol plus $10 \mathrm{ng} / \mathrm{ml}$ IGF-I or IGF-II, $1 \mathrm{ng} / \mathrm{ml}$ IGF-I or IGF-II, and $0.1 \mathrm{ng} / \mathrm{ml}$ IGF-I or IGF-II, as well as control and $45 \mathrm{mM}$ ethanol treatments. The Es class of treatments included $45 \mathrm{mM}$ ethanol plus 10nM Es, $1 \mathrm{nM}$ Es, and $0.1 \mathrm{nM}$ Es, as well as $45 \mathrm{mM}$ ethanol treatments. Control dishes were treated with DMEM only, and isovolumetric quantity of fluid per each dish was achieved by adding DMEM to each of the experimental treatment dishes. Cell viability was determined on DIV 5. 


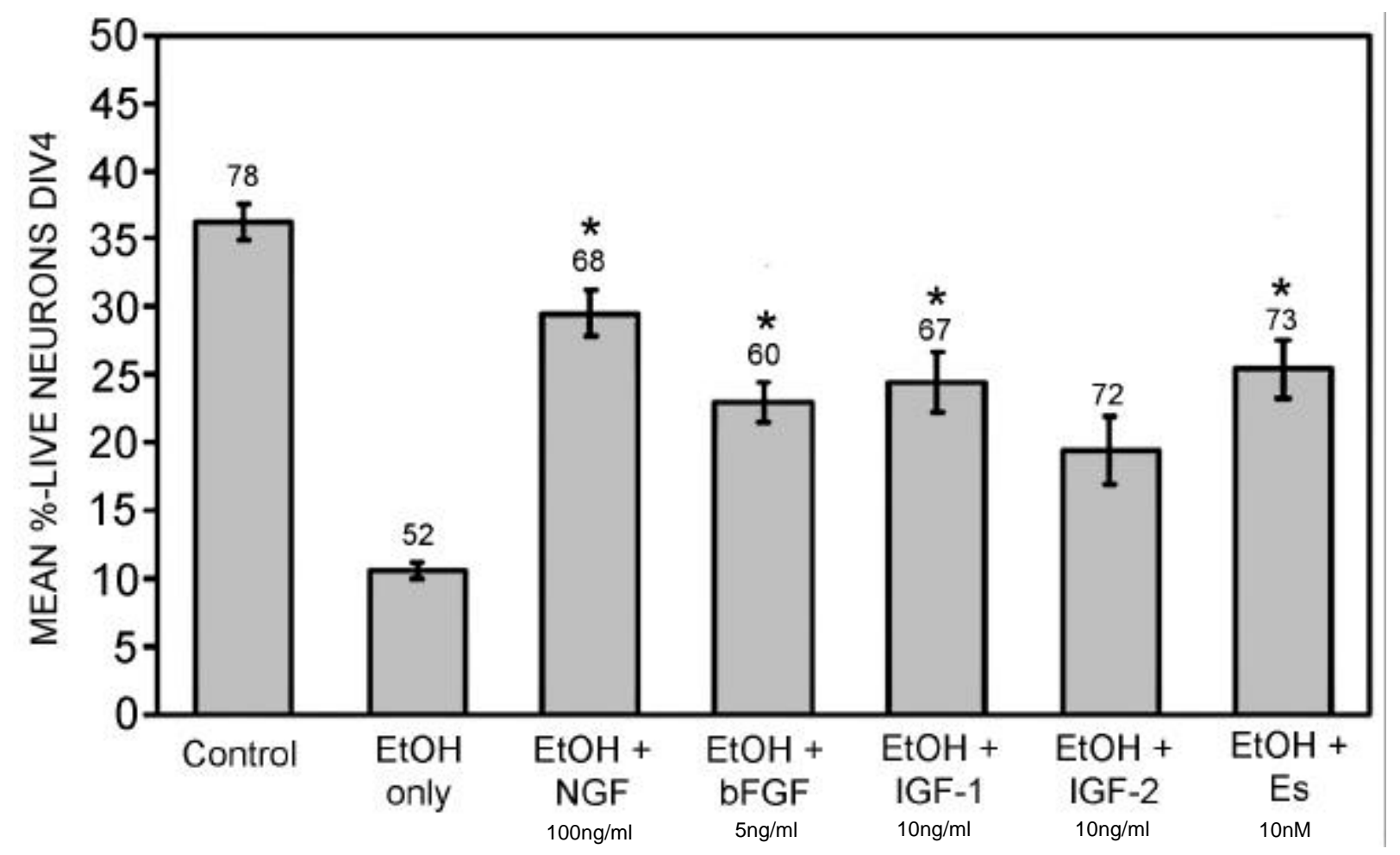

Figure 1. Cell viability on DIV 4 after chronic ethanol treatment $(45 \mathrm{mM})$. Ethanol and growth factors were added on DIV 1. Nine experiments are reported. Random microscopic fields were counted for living and dead cells by fluorescent microscopy. Viability is reported as the percent of live neurons remaining out of the total number of live and dead neurons per field. Stars indicate significant increases $(p<0.05$ in Dunnett's posttest) compared to the ethanol-only treatment group. The control group represents survival on DIV 4 with no ethanol treatment. Error bars $= \pm$ SEM. The number above the column represents the number of microscopic fields counted. DIV: day in vitro; SEM: standard error of the mean; EtOH: ethanol; NGF: nerve growth factor; bFGF: basic fibroblast growth factor; IGF-I/II: insulin-like growth factor I/II; Es: estrogen.

\section{Viability Assay}

Cell viability was determined using the intravital dyes fluorescein diacetate and propidium iodide (Sigma). Random fields of cells were examined immediately with a fluorescent microscope following exposure to the above dyes. Living and dead cells were expressed as a percentage of the total (38).

\section{Statistical Analyses}

Ethanol evaporation experiments

Ethanol samples were taken in triplicate from three separate culture dishes for a total of nine samples. Mean and SEM were calculated.

\section{Survival experiments}

Decisions on all statistical tests used the $\alpha=0.05$ level of significance. Sample mean values for cell survival were used in analysis of variance (ANOVA); the Dunnett's test for comparing a control mean to each other group mean was appropriate for this study $(39,40)$. A one-way ANOVA tested the hypothesis that there were no significant differences between sample means.

\section{Dose-dependence experiments}

The sample neurons were assigned to treatment with a randomized-block design. Decisions on all statistical tests used the $\alpha=0.05$ level of significance. Sample mean values for cell survival were used in ANOVA; the fixed effects model (Model-I ANOVA) was appropriate for this study (39-40). A one-way ANOVA tested the hypothesis that there were no significant differences between sample means. The one-way ANOVA included Scheffe's multiple contrasts method for comparison of treatment means (39). Pearson correlation coefficients were calculated within treatments for DIV 5 neuronal survival and treatment dosage.

\section{RESULTS}

\section{Neuronal Survival}

Previous data from this laboratory has shown that the cells in the neuronal plane were greater than $96 \%$ neuronal, as determined by staining for neurofilament proteins (41). Ninety-seven percent of the cells in the glial plane were glial cells, as determined by immunostaining for glial fibrillary acidic protein (GFAP). 


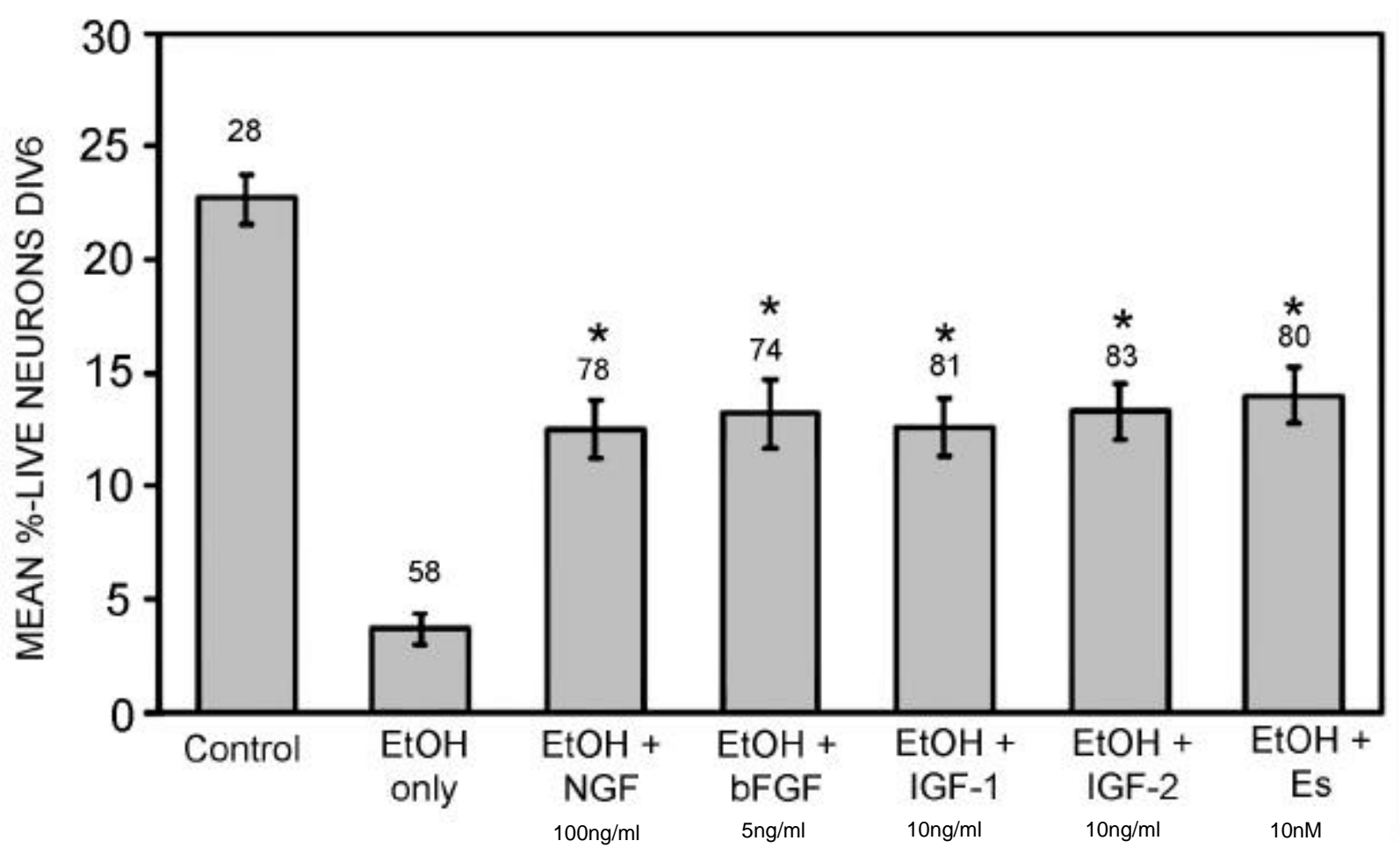

Figure 2. Cell viability on DIV 6 aftter chronic ethanol treatment $(45 \mathrm{mM})$. Ethanol and growth factors were added on DIV 1 and DIV 4 . Nine experiments are reported. Random microscopic fields were counted for living and dead cells by fluorescent microscopy. Viability is reported as the percent of live neurons remaining out of the total number of live and dead neurons per field. Stars indicate significant increases $(p<0.05$ in Dunnett's post-test) compared to the ethanol-only treatment group. The control group represents survival on DIV 6 with no ethanol treatment. Error bars $= \pm$ SEM. The number above the column represents the number of microscopic fields counted. DIV: day in vitro; SEM: standard error of the mean; EtOH: ethanol; NGF: nerve growth factor; bFGF: basic fibroblast growth factor; IGF-I/II: insulin-like growth factor I/II; Es: estrogen.

The neuronal survival on DIV 1 (prior to any treatment) for 82 fields counted was $86 \pm 1.1 \%$ (mean \pm SEM). Maximal percent cell survival on DIV 4 occurred in the control trial (containing no ethanol, and no growth factor), with $36.2 \pm 2.6 \%$ neuronal survival (Figure 1). The ethanol only treatment showed minimal cell survival with only $10.6 \pm 1.3 \%$ neuronal survival. Treatments with NGF and ethanol, bFGF and ethanol, IGF-I and ethanol, and Es and ethanol exhibited viability that was significantly increased over the ethanol-only treatment, while not significantly differing from control values ( $p<0.05$ in Dunnett's post-test).

On DIV 6, maximal cell survival occurred in the control trial, with $22.7 \pm 2.3 \%$ survival (Figure 2). Minimal cell survival was found in the ethanol only treatment group, with $3.7 \pm 1.3 \%$ neuronal survival. Treatments with NGF and ethanol, bFGF and ethanol, IGF-I and ethanol, IGF-II and ethanol, and Es and ethanol had percent cell survival values that were significantly increased over the ethanol-only treatment, and not significantly different from control values $(p<$ 0.05 in Dunnett's post-test).

\section{Dose-Dependence}

The effect of varying the concentration of growth factor/hormone on neuronal survival on DIV 5 is presented in Figure 3. For these experiments, the maximum control survival attained was $17.5 \pm 3.0 \%$ ( $n$ $=13$ ), and it occurred in the bFGF trial.

For the NGF treatments, maximal cell survival was observed in the $100 \mathrm{ng} / \mathrm{ml}$ NGF experiment, with a cell viability of $11.1 \pm 1.0 \%$ (Figure 3 ). Minimum cell survival was observed in the ethanol-only treatment, with $4.6 \pm 0.6 \%$ cell survival. Cell survival increased with the amount of NGF added. The $100 \mathrm{ng} / \mathrm{ml}$ and $10 \mathrm{ng} / \mathrm{ml}$ treatments of NGF plus ethanol were significantly increased over the ethanol-only treatment ( $p<0.05$ in Dunnett's post-test). However, the $1 \mathrm{ng} / \mathrm{ml}$ NGF plus ethanol treatment value was not found to differ significantly from the ethanol-only treatment value ( $p>0.05$ in Dunnett's post-test).

Maximal cell survival occurred in the $5 \mathrm{ng} / \mathrm{ml}$ bFGF plus ethanol treatment for the bFGF dose-dependence experiment (Figure 3), with a corresponding value of $17.7 \pm 4.3 \%$. The $5 \mathrm{ng} / \mathrm{ml}$ bFGF plus ethanol treatment 


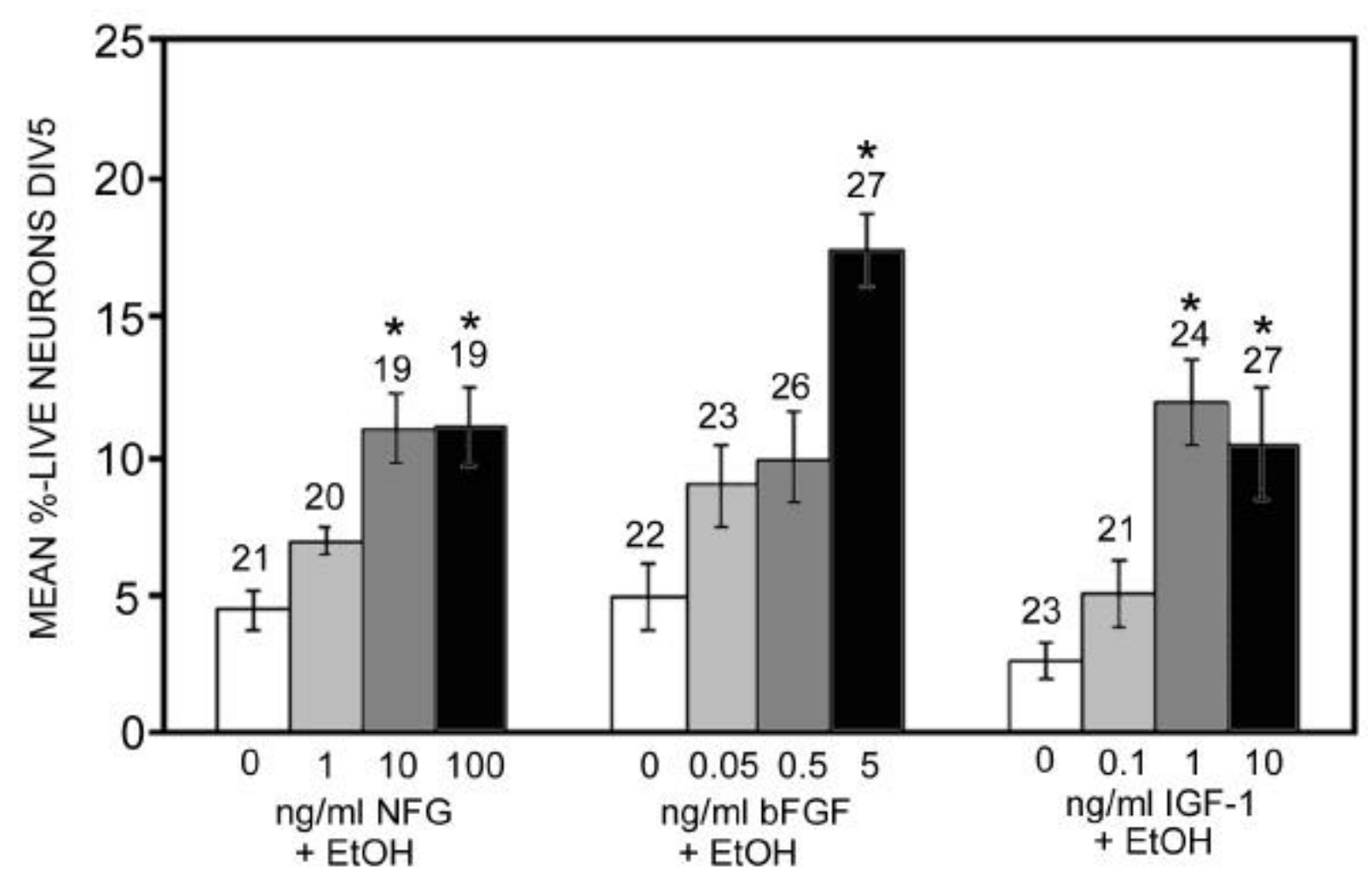

Figure 3. Effect of varying NGF, bFGF, and IGF-I dose on mean percent neuronal survival at DIV 5. Ethanol (45 mM) and growth factors were added on DIV 1, and DIV 4. Growth factor dosages shown are the original concentrations used in the previous survival experiments, plus 10 and 100 fold dilutions. Random microscopic fields were counted for living and dead cells by fluorescent microscopy. Viability is reported as the percent of live neurons remaining out of the total number of live and dead neurons per field. Stars indicate significant increases $(p<0.05$ in Dunnett's post-test) compared to the ethanol-only treatment group. Error bars $= \pm$ SEM. The number above the column represents the number of microscopic fields counted. DIV: day in vitro; SEM: standard error of the mean; EtOH: ethanol; NGF: nerve growth factor; bFGF: basic fibroblast growth factor; IGF-I: insulin-like growth factor I.

was the only treatment that is significantly increased over the ethanol-only value $(p<0.05$ in Dunnett's post-test).

The IGF-I dose-dependence experiment is also shown in Figure 3. Maximal cell survival is noted in the $1 \mathrm{ng} / \mathrm{ml}$ IGF-I plus ethanol treatment, with a value of $11.5 \pm 1.5 \%$. Both the $1 \mathrm{ng} / \mathrm{ml}$ and $10 \mathrm{ng} / \mathrm{ml}$ IGF-I plus ethanol treatments were found to be significantly different from the ethanol-only treatment $(p<0.05$ in Dunnett's post-test).

In the IGF-II and estrogen trials, neither 10 nor 100 fold dilutions of IGF-II plus ethanol, nor dilutions of Es plus ethanol significantly increased neuronal survival over the ethanol-only group ( $p>0.05$ in Dunnett's posttest). Thus, dose dependent relationships could not be established for these factors.

\section{DISCUSSION}

These results show that the neurotoxic effect of chronic ethanol treatment on fetal rat cortical neurons can be attenuated by simultaneous treatment with NGF, bFGF, IGF-I, IGF-II, or Es when ethanol and neuroprotective factors are administered on DIV 1 and 4 , though it should be noted that this neuroprotection did not result in levels of survival as high as control levels (i.e., with no ethanol). On DIV 4 neuronal survival was significantly increased compared to ethanol-only group in all groups except IGF-II (Figure 1), and by DIV 6, survival was significantly increased in all treatment groups (Figure 2). IGF-II did result in increased viability in the DIV 4 survival experiment, but this increase was not statistically significant compared to the ethanol-only survival values. On DIV 6 , after two treatments of ethanol and growth factors, the IGF-II treatment resulted in increases that were significantly increased over ethanol-only treatment values.

The dose-dependency experiments were conducted to help characterize the growth factor inhibition of ethanol's neurotoxicity. Logarithmic increases in growth factor concentration were found to increase the inhibition of ethanol's neurotoxicity at DIV 5 in the NGF, bFGF, and IGF-I trials (Figure 3). In the NGF trial, percent survival did not increase linearly with 
each increase in concentration of NGF but, rather, survival seemed to reach a plateau at the higher concentrations. This observation might reflect the plateau seen in a typical log dose-response curve (i.e., a sigmoidal curve), over a narrow range of NGF concentration. The NGF-mediated survival effect becomes saturated well below control levels of survival, which would rule the possibility that NGF is completely inhibiting the effects of ethanol on neurons. The observed survival effect may be due to saturation of the high affinity NGF receptor, TrkA, which is present on cortical neurons (25) although its expression varies throughout development (42). Nerve growth factor is neuroprotective in many cells (for review see (43)), protecting from stresses as varied as axotomy and oxidation $(16,17)$. Other labs have observed a similar dose dependency with $5 \mathrm{ng} / \mathrm{ml}$ NGF, but not with $0.1 \mathrm{ng} / \mathrm{ml}$ NGF protecting dorsal root ganglion neurons from ethanol (44).

Data from the bFGF trial exhibit a dose dependent relationship, with each increase in bFGF concentration resulting in increasing percent neuronal survival. While the trend observed is an increase in percent cell survival with increasing bFGF concentrations, only the highest concentration of bFGF $(5 \mathrm{ng} / \mathrm{ml})$ proved to be significantly increased over ethanol-only treatment values. Receptors for bFGF are present in the cortex (45) and receptor levels for bFGF reach a maximum in the rat brain at embryonic days 16 and 17 (46). Basic fibroblast growth factor is believed to be involved with neuroprotection because its mRNA is increased in response to insults such as seizure, head injury, cerebral contusions, and ischemia (47-50), and it blocks oxygen induced apoptosis in embryonic neurons (17).

In the IGF-I trial, an initial dose-response is followed by a small decrease in percent neuronal survival. This might be interpreted as another plateau effect, because there are relatively large SEM values at the two highest levels (Figure 3), and the reported drop-off in cell survival may be an artifact. This theory is supported by the fact that these two treatments are the only treatments in which the percent survival is significantly increased over the ethanol-only treatment, and statistical analysis showed that they were not significantly different from each other. It is possible, however, that the $10 \mathrm{ng} / \mathrm{ml}$ IGF-I treatment may be exhibiting a slight toxic effect. In this case, the $1 \mathrm{ng} / \mathrm{ml}$ IGF-I concentration can be viewed as giving a more positive pharmacological response with respect to inhibition of ethanol's toxic effects. In any case, further research needs to be conducted to titrate the optimum concentration of IGFI needed in this model system to attenuate ethanol's effects on neuronal survival.
Insulin-like growth factors-I and II play important roles in neuroprotection $(18,51)$. Genetic alteration of IGF-I leads to reduced brain size, decreased CNS myelination, and losses of particular neuronal subpopulations (52). Insulin like growth factor-I decreases neuronal loss due to hypoxic ischemia $(19,20)$ and both IGF-I and IGF-II decrease calciuminduced neuronal damage in the septum (18). Receptors for these factors are found in the cortex, and lesioning of the entorhinal cortex causes increases in receptor levels of IGF-I, IGF-II, and insulin receptors (53).

Dose-dependency for IGF-II and Es could not be established in this study. It is therefore possible that significant neuroprotection by IGF-II and Es only occurs at the higher doses (i.e., $\geq 10 \mathrm{ng} / \mathrm{ml}$ IGF-I, $\geq$ 10nM Es). Neuroprotection by estrogen has been documented in many other studies. Endogenous estrogen and Es receptors are found in cortical tissue (54). Estrogen treatment also has been shown to decrease the incidence and slow the onset of Alzheimer's disease (55). Gender differences in the onset and severity of degenerative diseases such as schizophrenia (56) give further support to the theory that Es is involved in neuroprotection. Higher doses of estrogen $(10 \mathrm{mM})$ have been found to protect neurons in the clonal hippocampal cell line HT22 from oxidative stresses such as glutamate, $\beta$-amyloid, and hydrogen peroxide, via a mechanism which is Es receptor independent (15).

On DIV 6 the overall protection provided by IGF-1 and IGF-II is similar (Figure 2), yet the DIV 4 data and dose experiment on DIV 5 exhibited different characteristics for IGF-I and IGF-II. Most studies indicate that the IGF-I receptor (tyrosine kinase) is responsible for the neuroprotective effects of IGFI/IGF-II $(57,58)$. Since IGF-I has a higher affinity for the IGF-I receptor than does IGF-II (58), one might expect to see more neuroprotection by IGF-I than IGFII at equivalent doses. The mannose-6-phosphate receptor is the IGF-II receptor, and is involved primarily in lysosomal sorting (59), although IGF-II also binds to the IGF-I receptor. It is important to note that we used equivalent nanogram doses in these experiments, but not equivalent molar doses. Thus, the above points may help explain why our data regarding neuroprotection by IGF-I and IGF-II are dissimilar. Future research involving the use of IGF-II and Es in this model system is needed in order to titrate concentrations for optimization of the response seen in the DIV 6 data (Figure 2).

There are a number of mechanisms by which these growth factors might be providing neuroprotection from 
the toxic effects of ethanol, including NGF binding new NGF receptors on ethanol-treated astrocytes, and prevention of calcium toxicity via expression of calcium binding proteins such as calbindin. Prenatal ethanol exposure leads to an increase in intracellular NGF in rat astrocytes, which is due to a decreased secretion of NGF by these astrocytes (60). Interestingly, low affinity NGF receptor (p75) expression is increased on the surface of these astrocytes (60). While the function of this increased low affinity NGF receptor expression is unknown, Valles et al. attribute it to an adaptive response to decreased NGF secretion, leading to prevention of ethanol's neurotoxicity (60). Therefore, it is possible that exogenous NGF binds to these additional NGF receptor molecules. In other areas, such as the cerebellum, ethanol, while not affecting NGF levels, causes a decrease in the NGF receptor levels (61). Thus, this response may depend on the area of the brain being studied.

Another possible mechanism for neuroprotection by growth factors involves their induction of the expression of calcium-binding proteins. Ethanol effects a host of plasma membrane channels leading to inactivation of certain channels and subsequent intracellular (toxic) accumulation of calcium (3). Sodium dependent calcium efflux has been observed in brain mitochondria exposed to low levels of ethanol (62). This transient increase in intracellular calcium can be ameliorated by the addition of NGF in cultured postnatal rat septal neurons (63). The calcium-binding protein calbindin is suspected of playing a role in growth factor-mediated neuroprotection, as there is evidence for an estrogen-responsive element upstream of the gene for calbindin (64). Research from this laboratory has shown that IGF-I, IGF-II, and NGF stimulate the production of calbindin immunoreactive neurons in the rat septal nucleus (unpublished data). Each calbindin protein molecule binds two $\mathrm{Ca}^{++}$ions (65). Thus calbindin may play a role in neuroprotection by binding some of the excess calcium that accumulates intracellularly due to ethanol.

Neuronal calcium toxicity and the effect of calciumbinding proteins has been discussed by others investigating gender differences in the response to ethanol treatment. In one study, the number of neurons containing the calcium-binding protein parvalbumin were decreased substantially in female rat offspring, but not male rat offspring in response to prenatal ethanol exposure (66). This suggests a mechanism for gender differences in some ethanol responses such as duration of ethanol preference, which is increased in female over male rats (67) as well as gender differences in both the occurrence of high blood alcohol levels and outcome for alcoholism treatment in humans $(68,69)$. Other responses such as response reaction time are not different in men and women (70).

Our experimental design involved administering ethanol chronically to fetal rat cortical neurons, in an effort to mimic the "binge-effect" that occurs when pregnant women drink excessively. The $45 \mathrm{mM}$ ethanol concentration used in these experiments is equivalent to a media concentration of $207 \mathrm{mg} / \mathrm{dl}$, or $0.21 \%$. The chronic nature of the treatment given is represented in the data from the ethanol evaporation experiment (Table 1). The original experimental ethanol concentration $(45 \mathrm{mM})$ decreased to $65.7 \%$ of its initial value after 6 hours in vitro to a concentration of $29.6 \mathrm{mM}$, which corresponds to $0.14 \%$. These blood alcohol levels occur in humans (71). Experiments in guinea pig demonstrate that ethanol crosses the placenta, with similar concentration-time curves in mother and fetus (72) in contrast to acetaldehyde which has a concentration less than one one-thousand that of the ethanol (72). Moderate levels of ethanol (33mM) do not alter gross physiological variables such as cerebral blood flow or oxygen or glucose consumption significantly in fetal sheep (73), thus suggesting that effects are due to damage at the cellular level.

The overall percent cell survival in this study was somewhat low, even in the control trials. Part of this can be attributed to the culture system used. This culture system is necessary, however, for successful interaction of ethanol and growth factors on neurons, without serum and without direct contact between the neurons and glia (see below). Also, there is low survival observed in the DIV 5 control experiments (see Results). This low value may be attributed in part to the small sample size for the reported control trial. It is also possible that a greater density of cells per field in the DIV 5 control trials compared to the DIV 4 and DIV 6 control trials may have slightly decreased cell survival. Statistical analyzes were conducted on the percent survival vs. the cell density (mean number cells per field). While no statistically significant relationship was established, a trend in decreasing cell survival with increasing density of cells per field was noted (data not shown).

Since both the neurons and the glia are present in the same media, one has to question whether the observed protective effects on neuronal survival are by direct effects on the neurons, by indirect effects mediated through the glia, or by a combination of the two. Growth factors with effects on neuronal development are produced differentially throughout the brain (74). Some glial cells may synthesize NGF, bFGF, IGF-I and IGF-II (60,75-77). Glial cells may also be responsive to these factors as they express IGF binding protein-2 (78), estrogen and bFGF receptors $(79,80)$ and are responsive 
to NGF (45) and bFGF (80). Nevertheless, glia are necessary to grow neurons in the absence of serum, and the endogenous production of growth factors by glial cells does not prevent the effects seen in response to the addition of exogenous factors at physiological concentrations $(30,41)$. Thus, while the stimulatory nature of these growth factors on neuron viability has been demonstrated, the mechanism for such actions need to be investigated further.

Ethanol is known to have various effects on neurons and glia, being toxic to neurons and decreasing the capacity of glial cells to support neurons. In rats, ethanol affects the plasma membrane of neurons and astrocytes by causing plasma protein defects (82). The surfaces of astrocytes smoothen with ethanol treatment when examined under electron microscopy (82). RNA and protein levels are decreased, but DNA levels are unchanged in astrocytes and neurons (82). Rats treated chronically with ethanol exhibit decreased glutamine synthetase activity in astrocytes and neurons, as well as altered isoforms of protein kinase $\mathrm{C}$, which may play a role in ethanol's neurotoxicity $(82,83)$. In the developing rat brain, ethanol treatment accelerates the transformation of radial glia into astrocytes, which leads to abnormal distribution of cortical neurons (11). Ethanol has also been shown to decrease glial mitosis (depending on the time frame of administration), to decrease mRNA for GFAP, to alter GFAP content and distribution in glia, and to induce oxidative stress in primary cultures of rat cortical astrocytes (84). As brain cells can synthesize acetaldehyde (4), this may be due to acetaldehyde which decreases growth in cultured rat astrocytes (85). Further work on growth factor alteration of ethanol effects on dendritic development is in progress by researchers in this laboratory.

Some of the effects of ethanol are due to alterations in growth factor function. Ethanol decreases the low affinity NGF receptor but not the high affinity Trk in cultured cortical neurons (25), while increasing the low affinity receptor content on the surface of glial cells and decreasing their NGF release (60). Ethanol also decreases bFGF stimulation of neurite outgrowth in hippocampal neurons (86). In contrast, ethanol enhances NGF and bFGF stimulation of neurite outgrowth in PC12 cells via activation of microtubule associated protein kinases (87). Maternal ethanol ingestion causes a decrease in brain IGF-I with a corresponding decrease in brain weight (88).

The question of whether the effects of ethanol are due to necrosis or apoptosis is unresolved. Research has demonstrated patterns of cellular death which are incompatible with apoptosis in cultured rat astrocytes in response to ethanol, that is, DNA fragmentation patterns that differ from those seen in programmed cell death (89). However, failure of neuronal migration due to altered interaction with laminin and subsequent apoptotic death has also been observed in ethanol models (90). These results showing that growth factors attenuate cell death caused by ethanol might provide insight into how ethanol kills neurons by identifying steps at which this process can be blocked, although this relies on the further elucidation of the mechanisms of these growth factors.

In this paper we have shown that several growth factors and Es can increase survival of ethanol challenged cortical neurons. Future experiments should include effects on neurite outgrowth, since neurite outgrowth is more sensitive to ethanol administration than is neuronal survival (44). Effects of growth factors and Es on the developing ethanol challenged fetal or neonatal human brain, as well as methods of delivery across the blood brain barrier (91) are areas of current study.

\section{ACKNOWLEDGMENTS}

Gratitude is extended to Tina Varkey, M.S., for her critical review, proofreading, and consultation. Tomas Lopez and Laura Mudd were supported by NIHNIGMS MBRS Grant GM 45455.

\section{REFERENCES}

1. Mattson SN and Riley EP. A review of the neurobehavioral deficits in children with fetal alcohol syndrome or prenatal exposure to alcohol. Alcoholism, Clinical and Experimental Research 22:279-294; 1998.

2. West, JR and Pierce, DR. Perinatal alcohol exposure and neuronal damage. In: West JR, ed. Alcohol and Brain Development. New York: Oxford University Press; 1986; 120157.

3. Michaelis E and Michaelis ML. Molecular events underlying the effects of ethanol on the developing central nervous system. In: West JR, ed. Alcohol and Brain Development. New York: Oxford University Press; 1986; 277-309.

4. Hamby-Mason R, Chen JJ, Schenker S, et al. Catalase mediates acetaldehyde formation from ethanol in fetal and neonatal rat brain. Alcoholism, Clinical and Experimental Research 21: 1063-1072; 1997.

5. Barnes DE and Walker DW. Prenatal ethanol exposure permanently reduces the number of pyramidal neurons in rat hippocampus. Developmental Brain Research 1: 333-340; 1981.

6. Miller MW and Riech RW. Effects of chronic ethanol administration of acetylcholinesterase activity in the somatosensory cortex and basal forebrain of the rat. Brain Research 627: 104-112; 1993.

7. Maier SE, Chen WJ, Miller JA, et al. Fetal alcohol exposure and temporary vulnerability regional differences in alcohol-induced microencephaly as a function of the timing of binge-like alcohol exposure during rat brain development. Alcoholism, Clinical and Experimental Research 21: 1418-1428; 1997.

8. Nagahare AH and Handa RJ. Fetal alcohol exposure produces delay-dependent memory deficits in juvenile and adult rats. Alcoholism, Clinical and Experimental Research 21: 710-715; 1997. 
9. Furuya H, Aikawa H, Yoshida T, et al. Effects of ethyl alcohol administration to THA rat dams during their gestation period on learning behavior and on levels of monoamines and metabolites in the brains of pups after birth. Alcoholism, Clinical and Experimental Research 20: 305A-310A; 1996.

10. Maier SE, Chen WJ and West JR. Prenatal binge-like alcohol exposure alters neurochemical profiles in fetal rat brain. Pharmacology Biochemistry and Behavior 55: 521-529; 1996.

11. Miller MW and Robertson S. Prenatal exposure to ethanol alters the postnatal development and transformation of radial glia to astrocytes in the cortex. Journal of Comparative Neurology 337: 253-266; 1993.

12. Samson HH. Microcephaly and fetal alcohol syndrome: human and animal studies. In: West JR, ed. Alcohol and Brain Development; New York: Oxford University Press; 1986; 167183.

13. Miller MW and Potempa G. Numbers of neurons in mature rat somatosensory cortex: effects of prenatal exposure to ethanol. Journal of Comparative Neurology 293: 92-102; 1990.

14. Miller MW. Effect of pre- or postnatal exposure to ethanol on the total number of neurons in the principal sensory nucleus of the trigeminal nerve: cell proliferation and neuronal death. Alcoholism, Clinical and Experimental Research 19: 1359$1363 ; 1995$.

15. Behl C, Widmann M, Trapp T, et al. 17-beta estradiol protects neurons from oxidative stress-induced cell death in vitro. Biochemical and Biophysical Research Communications 216:473-482; 1995.

16. Williams LR, Varon S, Peterson GM, et al. Continuous infusion of nerve growth factor prevents basal forebrain neuronal death after fimbria fornix transection. Proceedings of the National Academy of Sciences (USA) 83: 9231-9235; 1986.

17. Satoh T, Enokido Y, Kuto T, et al. Oxygen toxicity induces death in neuronal cells. Cellular and Molecular Neurobiology 18:649666; 1998.

18. Cheng B and Mattson MP. IGF-I and IGF-II protect cultured hippocampal and septal neurons against calcium-mediated hypoglycemic damage. Journal of Neuroscience 12: 1558-1566; 1992.

19. Gluckman P, Klempt N, Guan J, et al. A role for IGF-1 in the rescue of CNS neurons following hypoxic-ischemic injury. Biochemical and Biophysical Research Communications 182: 593-599; 1992.

20. Guan J, Williams C, Gunning M, et al. The effects of IGF-1 treatment after hypoxic-ischemic brain injury in adult rats. Journal of Cerebral Blood Flow Metabolism 13: 609-616; 1993.

21. Luo $\mathrm{J}$ and Miller MW. Growth factor-mediated neural proliferation: target of ethanol toxicity. Brain Research Brain Research Reviews 27:157-167; 1998.

22. Luo J, West JR, and Pantazis NJ. NGF and bFGF protect rat cerebellar granule cells in culture against ethanol-induced cell death. Alcoholism, Clinical and Experimental Research 21:1108-1120; 1997.

23. Heaton MB, Paiva M, Swanson DJ, et al. Responsiveness of cultured septal and hippocampal neurons to ethanol and neurotrophic substances. Journal of Neuroscience Research 39:305-318; 1994.

24. Mitchell JJ, Paiva M, Moore DB, et al. A comparative study of ethanol, hypoglycemia, hypoxia and neurotrophic factor interactions with fetal rat hippocampal neurons: a multi-factor in vitro model developmental ethanol effects. Brain Research Developmental Brain Research 105:241-250; 1998.

25. Seabold GK, Luo J and Miller MW. Effect of ethanol on neurotrophin-mediated cell survival and receptor expression in cultures of cortical neurons. Brain Research Developmental Brain Research 108: 139-45; 1998.
26. Rahman H, Kentroti $\mathrm{S}$ and Vernadakis A. The critical period for ethanol effects in cholinergic neuronal expression in neuroblast enriched cultures derived from 3-day-old chick embryo:NGF ameliorates the cholinotoxic effects of ethanol. International Journal of Developmental Neuroscience 12:397-404; 1994.

27. Pucilowski O, Ayensy WK, and D'Ercole AJ. Insulin-like growth factor I expression alters acute sensitivity and tolerance to ethanol in transgenic mice. European Journal of Pharmacology 305:57-62; 1996.

28. Carter A, and Soliman MR. Estradiol alters ethanol-induced effects on beta-endorphin and met-enkephalin levels in specific brain regions in ovariectomized rats. Pharmacology 53:143-150; 1996.

29. Backstrom M, Hall K, and Sara V. Somatomedin levels in cerebrospinal fluid in adults with pituitary disorders. Acta Endocrinologica 107:171-178; 1984

30. Downen ML, Mudd LM, Roback JD, et al. Early nerve growth factor induced events in developing rat septal neurons. Developmental Brain Research 74: 1-13; 1993.

31. Cao W, Wen R, Li F, et al. Induction of basic fibroblast growth factor mRNA by basic fibroblast growth factor in Muller cells. Investigative Opthalmology and Visual Science 38:1358-66; 1997.

32. Himmelseher S, Pfenniger E, and Georgieff M. The effect of basic fibroblast growth factor on glutamate-injured neuroarchitecture and arachidonic acid release in adult hippocampal neurons. Brain Research 707:54-63; 1996.

33. Zheng $\mathbf{J}$ and Ramirez VD. Demonstration of membrane estrogen binding proteins in rat brain by ligand blotting using a 17betaestradiol-[125I]bovine serum albumin conjugate. Journal of Steroid Biochemistry and Molecular Biology 62:327-336; 1997.

34. Banker, GA and Cowan WM. Rat hippocampal neurons in dispersed cell culture. Brain Research 126: 397-425; 1977.

35. Banker, GA, and Cowan, WM. Further observations on hippocampal neurons in dispersed cell culture. Journal of Comparative Neurology 187: 469-494; 1979.

36. Banker GA. Trophic interactions between astroglial cells and hippocampal neurons in culture. Science 209: 809-810; 1980.

37. Juosimma J, Merenmies J and Rauvala H. Neurite outgrowth of neuroblastoma cells induced by proteins covalently coupled to glass coverslips. European Journal of Cell Biology 35: 55-61; 1984.

38. Jones $\mathrm{KH}$ and Senft JA. Simultaneous use of fluorescein diacetate (FDA) and propidium iodide (PI) to assess culture viability. Journal of Histochemistry and Cytochemistry 33: 7779; 1985.

39. Sokal RR and Rohlf FJ. Biometry (3rd Edition). New York: WH Freemen and Company; 1995.

40. Zar JH. Biostatistical Analysis (3rd Edition); Upper Saddle River, New Jersey: Prentice-Hall; 1996.

41. Mudd LM, Torres J, Lopez T, Montague J. Effects of growth factors and estrogen on the development of septal cholinergic neurons from the rat. Brain Research Bulletin 45: 137-142; 1998.

42. Allendoerfer KL, Shelton DR, Shooter EM, et al. Nerve growth factor receptor immunoreactivity is transiently associated with the subplate neurons of the mammalian cerebral cortex. Proceedings of the National Academy of Sciences (USA) 87: 187-190; 1990.

43. Connor B and Dragunow M. The role of neuronal growth factors in neurodegenerative disorders of the human brain. Brain Research Brain Research Reviews 27:1-39; 1998.

44. Heaton MB, Paiva M, Swanson DJ, et al. Modulation of ethanol neurotoxicity by nerve growth factor. Brain Research 620:7885; 1993.

45. Yuguchi T, Kohmura E, Yamada K, et al. Messenger RNA and 
protein expression of basic fibroblast growth factor receptor after cortical ablation. Brain Research Molecular Brian Research 25:50-56; 1994.

46. Grothe $\mathrm{C}$ and Meisinger C. Fibroblast growth factor (FGF)-2 sense and antisense mRNA are present in the adult rat nervous system: specific detection by nuclease protection assay. Neuroscience Letters 197:175-178; 1995.

47. Kumon Y, Sasaki S, Kadota O, et al. Transient increase in endogenous basic fibroblast growth factor in neurons of ischemic rat brains. Brain Research 605: 169-174; 1993.

48. Gall CM, Berschauer R and Isackson PJ. Seizures increase basic fibroblast growth factor mRNA in adult rat forebrain neurons and glia. Brain Research Molecular Brain Research 21: 190$205 ; 1994$.

49. Iwamoto Y, Yamaki T, Murakami N, et al. Basic fibroblast growth factor messenger RNA is expressed strongly at the acute stage of cerebral contusion. Life Sciences 55: 1651-1656; 1994.

50. Frank E and Ragel B. Cortical basic fibroblast factor expression after head injury: preliminary results. Neurological Research 17 : 129-131; 1995.

51. Resnicoff M, Rubini M, Baserga, R, et al. Ethanol inhibits insulin-like growth factor-1-mediated signalling and proliferation of C6 rat glioblastoma cells. Laboratory Investigation 71: 657-662; 1994.

52. Beck KD, Powell-Braxton L, Widmer GR, et al. IGF-1 gene disruption results in reduced brain size, CNS hypomyelination, and loss of hippocampal granule and striatal parvalbumincontaining neurons. Neuron $14: 717-730 ; 1995$.

53. Kar S, Bacciechet A, Quirion R, et al. Entorhinal cortex lesion induces differential responses in [125I] insulin-like growth factor $1,\left[{ }^{125} \mathrm{I}\right]$ insulin-like growth factor II and $\left[{ }^{125} \mathrm{I}\right]$ insulin receptor binding sites in the rat hippocampal formation. Neuroscience 55: 69-80; 1993

54. Simerly RB, Chang C, Muramatsu M, et al. Distribution of androgen and estrogen receptor mRNA-containing cells in the rat brain: an in situ hybridization study. Journal of Comparative Neurology 294: 76-95; 1990.

55. Gibbs RB. Estrogen and nerve growth factor-related systems in brain. Effects on basal forebrain cholinergic neurons and implications for learning and memory processes and aging. Annals of the New York Academy of Sciences 743: 165-196; 1994.

56. Hafner $\mathrm{H}$, Heiden $\mathrm{W}$, Hambrecht $\mathrm{M}$, et al. A chapter in systematic schizophrenia research, the search for causal explanations for sex differences in age of onset. Nervenarzt 64: 706-716; 1993.

57. D'Ercole AJ, Ye P, Calikoglu AS and Gutierrez-Ospina G. The role of insulin-like growth factors in the central nervous system. Molecular Neurobiology 13: 227-255; 1996.

58. Olson BR, Scott DC, Wetsel WC, et al. Effects of insulin-like growth factors I and II and insulin on the immortalized hypothalamic GTI-7 cell line. Neuroendocrinology 62:155-165; 1995.

59. Cataldo AM, Hamilton DJ, Barnett JL, et al. Properties of the endosomal-lysosomal system in the human central nervous system: disturbances mark most neurons at risk to degenerate in Alzheimer's disease. Journal of Neuroscience 16:186-199; 1996.

60. Valles S, Lindo L, Montoliu C, et al. Prenatal exposure to ethanol induces changes in nerve growth factor and its receptor in proliferating astrocytes in primary culture. Brain Research 656: 281-286; 1994.

61. Dohrman DP, West JR and Pantazis NJ. Ethanol reduces expression of the nerve growth factor receptor but not nerve growth factor protein levels in the neonatal rat cerebellum. Alcoholism Clinical and Experimental Research 21: 882-893;
1997.

62. Rottenberg $\mathrm{H}$ and Marbach M. Alcohol stimulates $\mathrm{Na}^{+} / \mathrm{Ca}^{++}$ exchange in brain mitochondria. Life Sciences 48:987-994; 1991.

63. Webb B, Suarez SS, and Heaton MB. Cultured post-natal rat medial septal neurons respond to acute ethanol treatment and nerve growth factor by changing intracellular calcium levels. Alcoholism, Clinical and Experimental Research 20: 13851394; 1996.

64. Darwish H, Krisinger J, Furlow JD, et al. An estrogenresponsive element mediates the transcriptional regulation of calbindin D-9K gene in rat uterus. Journal of Biological Chemistry 266: 551-558; 1991.

65. Szebenyi DM and Moffat K. The refined structure of Vitamin-D dependent calcium-binding protein from bovine intestine. Journal of Biochemistry 26: 8761-8777; 1985.

66. Moore DB, Ruygrot AC, Walker DW, et al. Effects of prenatal ethanol exposure on parvalbumin-expressing GABAergic neurons in the adult rat medial septum. Alcoholism, Clinical and Experimental Research 21: 849-856; 1997.

67. Almeida OF, Shoaib M, Deicke J, et al. Gender differences in ethanol preference and ingestion in rats. Journal of Clinical Investigation 101: 2677-2685; 1998.

68. Teplin LA, Abram KM and Michaels SK. Blood alcohol level among emergency room patients: a multivariate analysis. Journal of Studies on Alcohol 50:441-447; 1989.

69. Sanchez-Craig M, Leigh G, Spivak K, et al. Superior outcome of females over males after brief treatment for the reduction of heavy drinking. British Journal of Addiction. 84:395-404; 1989.

70. Mulvihill LE, Skilling TA and Vogel-Sprott M. Alcohol and the ability to inhibit behavior in men and women. Journal of Studies on Alcohol 58: 600-605; 1997.

71. Marowitz LA. Predicting DUI recidivism: blood alcohol concentration and driver factors. Accident Analysis and Prevention 30:545-554; 1998.

72. Clarke DW, Steenaart NA, Slack CJ, et al. Pharmacokinetics of ethanol and its metabolite, acetaldehyde, and fetolethality in the third trimester pregnant guinea pig for oral administration of acute, multiple-dose ethanol. Canadian Journal of Physiology and Pharmacology 64:1060-1067; 1986.

73. Gleason CA and Hotchkiss KJ. Cerebral responses to acute maternal alcohol intoxication in immature fetal sheep. Pediatric Research 31:645-648; 1992.

74. LeRoux PD and Reh TA. Regional differences in glial-derived factors that promote dendritic outgrowth from mouse cortical neurons in vitro. Journal of Neuroscience 14: 4639-4655; 1994.

75. Gray CW and Patel AJ. Characterization of a neurotrophic factor produced by cultured astrocytes involved in the regulation of subcortical cholinergic neurons. Brain Research 574: 257$265 ; 1992$.

76. McKelvie PA, Rosen KM, Kinney HC, et al. Insulin-like growth factor II expression in the developing human brain. Journal of Neuropathology and Experimental Neurology 51: 464-471; 1992.

77. Garcia-Estrada J, Garcia-Segura LM and Torres-Aleman I. Expression of insulin-like growth factor I by astrocytes in response to injury. Brain Research 592: 343-347; 1993.

78. Lee WH, Javedan S and Bondy CA. Coordinate expression of insulin-like growth factor system components by neurons and neuroglia during retinal and cerebellar development. Journal of Neuroscience 12: 4737-4744; 1992.

79. Sangati S, Melcangi RC, Celotti F, et al. Estrogen receptor is expressed in different types of glial cells in culture. Journal of Neurochemistry 63: 2058-2064; 1994.

80. Miyagi N, Kato S, Terasaki M, et al. Fibroblast growth factor-9 (glia-activating factor) stimulates proliferation and production 
of glial fibrillary acidic protein in human gliomas either in the presence or in the absence of the endogenous growth factor expression. Oncology Reports 6:87-92; 1999.

81. Yokoyama M, Black IB and Dreyfus CF. Nerve growth factor increases brain astrocyte number in culture. Experimental Neurology 124: 377-380; 1993.

82. Babu PP, Kumari LR and Vemuri MC. Differential changes in cell morphology, macromolecular composition and membrane protein profiles of neurons and astrocytes in chronic ethanol treated rats. Molecular and Cellular Biochemistry 130: 29-40; 1994.

83. Mahadev K and Vemuri MC. Selective changes in protein kinase $\mathrm{C}$ isoforms and phosphorylation of endogenous substrate proteins in rat cerebral cortex during pre-and postnatal ethanol exposure. Archives of Biochemistry and Biophysics 356: 249257; 1998.

84. Guerri C and Renau-Piqueras J. Alcohol, astroglia, and brain development. Molecular Neurobiology 15: 65-81; 1997.

85. Holownia A, Ledig M, Mapoles J, et al. Acetaldehyde-induced growth in cultured rat astroglial cells. Alcohol 13: 93-97; 1996.

86. Heaton MB, Paiva M, Swanson DJ, et al. Alterations in responsiveness to ethanol and neurotrophic substances in fetal septohippocampal neurons following chronic prenatal ethanol exposure. Brain Research Developmental Brain Research 85:1$13 ; 1995$.

87. Roivanen R, Hundle B and Messing RO. Ethanol enhances growth factor activation of mitogen-activated protein kinases by a protein kinase C-dependent mechanism. Proceedings of the National Academy of Sciences (USA) 92:1891-1895; 1995.

88. Singh SP, Ehmann S and Snyder AK. Ethanol-induced changes in insulin-like growth factors and insulin-like growth factor gene expression in the fetal brain. Proceedings of the Society for Experimental Biology and Medicine 212: 349-354; 1996.

89. Holownia A, Ledig M and Menez JF. Ethanol-induced cell death in cultured rat astroglia. Neurotoxicology and Teratology 19: 141-146; 1997.

90. Liesi P. Ethanol exposed central neurons fail to migrate and undergo apoptosis. Journal of Neuroscience Research 48: 439448; 1997.

91. Granholm AC, Albeck D, Backman C, et al. A non-invasive system for delivering nerve growth factors across the bloodbrain barrier: a review. Reviews in the Neurosciences 9:31-55; 1998.

Jason A. Zell, M.S., recently completed his second year the D.O./M.P.H. program at Nova Southeastern University College of Osteopathic Medicine (Fort Lauderdale, Florida, USA). Tomas F. Lopez, B.S., is a research assistant at the Miami Project to Cure Paralysis of the University of Miami (Miami, Florida, USA). Jeremy R. Montague, Ph.D., holds a Professorship at Barry University, School of Natural and Health Sciences (Miami Shores, Florida, USA), and Laura M. Mudd is an Associate Professor at the same institution. 